\title{
TENOTOMY WITH OR WITHOUT TENODESIS OF THE LONG HEAD OF THE BICEPS USING REPAIR OF THE ROTATOR CUFF
}

\begin{abstract}
Roberto Yukio Ikemoto', Paulo Eduardo Pileggi ${ }^{2}$, Joel Murachovsky ${ }^{3}$, Luís Gustavo Prata Nascimento ${ }^{4}$, Rogerio Bueno Serpone ${ }^{4}$,
\end{abstract} Eric Strose ${ }^{4}$, Luiz Henrique Almeida Oliveira ${ }^{5}$

\begin{abstract}
Objective: To compare the functional results among patients undergoing tenotomy with or without tenodesis of the long head of the biceps associated with arthroscopic repair of rotator cuff injuries, with a minimum two-year follow-up. Method: This was a retrospective non-randomized trial with evidence level III, in which the medical files of 77 patients with lesions of the long head of the biceps were reviewed and clinically reassessed. Among these, 55 patients underwent tenotomy without tenodesis and 22 underwent tenotomy with tenodesis, with outpatient follow-up for at least two years. The age, dominant side, operated side, lesion size using the Gartsman classification, pre and postoperative range of motion, presence or absence of the Popeye sign, pain in the bicipital groove and assessments using
\end{abstract}

the University of California at Los Angeles (UCLA) score and the elbow strength index. Results: The mean UCLA score of the sample went from 16.92 (range: 8 to 25 ) to 31.45 (range: 13 to 35$)(p<0.001)$. Comparison of the pre and postoperative UCLA scores in the two groups showed that the difference in the group with tenotomy and tenodesis was 15.95 and in the group with tenotomy alone, $14.62(\mathrm{p}=0.023)$. However, there was no statistical significance in comparing the groups regarding pain in the bicipital groove, Popeye sign or elbow strength index. Conclusion: This study showed that the difference in UCLA scores was statistically significant. The group with tenotomy and tenodesis of the long head of the biceps presented better functional results.

Keywords - Rotator Cuff, Tenotomy, Tenodesis, Arm Bones

\section{INTRODUCTION}

The biceps brachii muscle is located in the anterior compartment of the arm, and the proximal portion is divided into two tendons: the long head of the biceps (LHB) and the short head of the biceps (SHB). The origin of the SHB is located in the coracoid process and that of the LHB is in the supraglenoidal tubercle of the scapula. The insertion is located on the tuberosity of the radius and the deep fascia of the forearm. The tendon of the LHB has a rounded shape, is surrounded by the synovial membrane, and traverses the intertubercular groove at the proximal humeral joint. Its function is to depress the humeral head in the glenoid; it performs supination of the forearm and performs elbow flexion when the forearm is supinated ${ }^{(1)}$.

During arthroscopic repair of the rotator cuff, the association of lesions of the long head of the biceps with less than $25 \%$ involvement were treated with debridement ${ }^{(2,3)}$. However, there is no consensus for lesions larger than $25 \%$, whose options are tenotomy with or without tenodesis ${ }^{(4,5)}$.

Both treatments have shown satisfactory clinical results ${ }^{(5,6)}$. Authors who support only tenotomy ${ }^{(7,8)}$ state that it is a technically simple procedure, allowing for early rehabilitation and resulting in symptom improvement. However, it may lead to biomechanical

1 - Professor; Head, Orthopedics and Traumatology Clinic of the Hospital Ipiranga; Head, Shoulder and Elbow Group of the Hospital Ipiranga, São Paulo, SP, and the ABC School of Medicine, Santo André, SP, Brazil.

2 - Medical Intern in Shoulder and Elbow Surgery, ABC School of Medicine, Santo André, SP, and Hospital Ipiranga, São Paulo, SP, Brazil.

3 - Professor; Assistant Physician, Shoulder and Elbow Group, ABC School of Medicine, Santo André, SP.

4 - Master's degree in Orthopedics; Assistant Physician, Shoulder and Elbow Group, ABC School of Medicine, Santo André, SP.

5 - Assistant Physician, Shoulder and Elbow Group, ABC School of Medicine, Santo André, SP.

Study conducted at the Department of Diseases of the Locomotor Apparatus, ABC School of Medicine. Director: Prof. Dr. Carlo Milani.

Correspondence: Rua Monte Alegre, 253, 121 - São Caetano do Sul, SP. Email: rob.ike@hotmail.com

Received for publication: 1/10/2012, accepted for publication: 4/12/2012.

The authors declare that there was no conflict of interest in conducting this work 
changes such as loss of strength of elbow flexion and supination, and eventual cosmetic deformity (Popeye sign $)^{(2,9)}$. Other authors advocate tenotomy combined with tenodesis ${ }^{(9,10)}$, due to patients maintaining flexion and supination strength without showing the Popeye sign.

Some surgeons have adopted age and physical activities as criteria for choosing the treatment for lesions of the LHB. They consider tenotomy alone for patients above 55 years of age with low functional demands. In patients below that age or those who perform intense work activities, they opt for tenotomy combined with tenodesis ${ }^{(2,11,12)}$.

The goal is to compare the functional results in patients undergoing tenotomy with or without LHB tenodesis combined with arthroscopic repair of a rotator cuff injury, with a follow-up period greater than two years.

\section{METHODS}

We performed a retrospective, non-randomized study, with evidence level III, of 162 patients undergoing arthroscopic repair of the rotator cuff of the shoulder, with a follow-up period longer than two years, with LHB injuries justifying tenotomy with or without tenodesis.

Inclusion criteria were rotator cuff injury associated with LHB injury in which full arthroscopic repair was performed and more than two years of follow-up. Exclusion criteria were patients followed less than two years, prior surgical procedures, partial lesions, extensive lesions for which full repair was not possible, or when only debridement was performed.

Of the 162 patients, 63 did not undergo outpatient treatment (seven deaths) and 22 met the exclusion criteria of the study, comprising a total of 77 patients. Fifty-five patients $(71.42 \%)$ underwent tenotomy alone and $22(28.57 \%)$ underwent tenotomy with tenodesis.

The LHB tenodesis was performed by suturing the tendon in the intertubercular groove with two anchors, above the insertion of the pectoralis major tendon.

The University of California at Los Angeles (UCLA) ${ }^{(13)}$ scale was used to compare shoulder function. The scale uses five parameters for the assessment of the shoulder: pain, function, active flexion, muscle strength in active flexion, and patient satisfaction. Points are awarded for each criterion and the final sum defines the result as poor (0-20), fair (21-27), good (28-33), or excellent (34-35). The Elbow Strength Index (ESI) ${ }^{(14)}$ was used for the evaluation of elbow flexion strength. The ESI is the ratio of the strength of elbow flexion on the affected side and the contralateral side, as measured by a portable digital dynamometer Kern ${ }^{\circledR}$ CH50K50 model with a capacity of 50 kilograms $(\mathrm{kg})$ and accuracy of 50 grams $(\mathrm{g})$.

We observed a correlation between the dominant side and the operated side in all patients studied. An increase in range of motion (elevation, medial, and lateral rotation) was also assessed after the surgical procedure.

The lesions of the rotator cuff were classified during the arthroscopic procedure and defined as "minor lesions" (small and medium) or "large lesions" (large and extensive), according to the classification set forth by Gartsman ${ }^{(15)}$. We evaluated the relationship between lesion size and the ESI and preoperative UCLA score.

The parameters for benchmarking between groups were age, length of follow-up, pain in the intertubercular groove, ESI, presence or absence of the Popeye sign and variation in the UCLA (pre- and postoperative) scores.

\section{STATISTICAL ANALYSIS}

In the statistical analysis we adopted a significance level of $5 \%(0.05)$ for the statistical tests. We used SPSS (Statistical Package for Social Sciences) version 19.0.

We used Fisher's exact test to assess the statistical relationship between dominance and the operated side. To compare each patient's pre- and postoperative evaluation, we applied the Wilcoxon signed rank test for the UCLA, ROM, and ESI variables. For the comparison between the lesion subtypes (small and large) for the ESI and preoperative UCLA variables, we applied the Mann-Whitney test.

We used Fisher's exact test in the evaluation between groups to compare pain in the bicipital groove and the presence or absence of the Popeye sign. For age, length of follow-up, ESI, and UCLA score, we used the Mann-Whitney test.

\section{RESULTS}

The operated side was dominant in $56(72.72 \%)$ patients, the operated side was not dominant in 21 
$(27.28 \%)$. In the analysis, statistical significance was found between the operated side and the dominance of the patient $(\mathrm{p}=0.005)$.

With respect to the pre- to postoperative changes in ROM for all of the patients, the average elevation of the shoulder went from $137.73^{\circ}$ (range $60^{\circ}$ to $160^{\circ}$ ) to $155.78^{\circ}$ (range $90^{\circ}$ to $\left.160^{\circ}\right)(\mathrm{p}<0.01)$, the lateral rotation went from $53.70^{\circ}$ (range $20^{\circ}$ to $80^{\circ}$ ) to $61.04^{\circ}$ (range $30^{\circ}$ to $\left.80^{\circ}\right)(\mathrm{p}<0.01)$, and medial rotation went from T12 (range of the greater trochanter of the proximal femur to T5) to T10 (range of the greater trochanter of the proximal femur to T5) $(\mathrm{p}=0.05)$. The increase in the values of all parameters was statistically significant (Table 1).

Lesions were classified as small in 27 patients, and as large in 28 patients who underwent tenotomy without tenodesis. In the patients who underwent tenotomy with tenodesis, 10 lesions were classified as small and 12 as large. These results fostered comparative evaluations of the ESI according to lesion size between groups (Table 2). There was no statistical significance between ESI and the size of lesions.

The correlation between lesion size and the average preoperative UCLA score was investigated. Patients with lesions classified as small had an average preoperative UCLA score of 16.62 (8 to 24) and those classified as large lesions had an average preoperative UCLA score of 17.2 ( 9 to 25$)(p=0.659)$. There was no statistically significant difference between lesion size and preoperative UCLA score (Table 3).

The mean age of patients in the group subjected only to tenotomy was 58.05 years (46 to 81 ) and those in the group with tenotomy and tenodesis was 58.18 years (46 to 66). The mean follow-up of the tenotomy without tenodesis group was 41.84 months (26 to 66) and that of the tenotomy with tenodesis group was 45.36 months (24 to 76) (Table 4). We did not detect statistical significance when comparing age (years) and length of follow-up (months) between groups.

Three patients in the group undergoing tenotomy with tenodesis $(13.6 \%)$ and three patients in the tenotomy without tenodesis group $(5.5 \%)$ complained of pain on active flexion of the elbow against resistance and pain on palpation along the length of the biceps $(p=0.345)$. The mean ESI was 0.98 in the tenotomy with tenodesis group and 0.96 in the group with only tenotomy $(p=0.955)$. In the tenotomy with tenodesis group, two patients $(9.10 \%)$ were positive for the Popeye sign, while 12 patients $(21.80 \%)$ presented the sign in the group with only tenotomy $(\mathrm{p}=$ 0.327). There was no statistical significance between the groups in the above parameters analyzed (Table 5).

The average UCLA score for the total sample went from 16.92 (8 to 25$)$ to 31.45 (13 to 35$)$ ( $p<0.001)$. Comparing the changes in the UCLA score pre- to postoperatively between the two groups, in the patients undergoing tenotomy with tenodesis this change was 15.95 points, and in patients undergoing only tenotomy, the change was $14.62(\mathrm{p}=0.023)$. This result was statistically significant (Table 6).

Table 1 - Preoperative vs postoperative clinical patient evaluation.

\begin{tabular}{c|c|c}
\hline Elevation pre & Elevation post & $\mathbf{p}$ \\
\hline 137.73 & 155.78 & $<0.01$ \\
\hline Lateral rotation pre & Lateral rotation post & \\
\hline 53.7 & 61.04 & $<0.01$ \\
\hline Medial rotation pre & Medial rotation post & \\
\hline T12 & T10 & 0.05 \\
\hline
\end{tabular}

Table 2 - Comparison between size of lesions and muscular strength between groups.

\begin{tabular}{c|c|c|c|c|c}
\hline Variable & Group & Lesion & $\mathbf{N}$ & Mean ESI & $\mathbf{p}$ \\
\hline \multirow{4}{*}{$\begin{array}{c}\text { Elbow } \\
\text { Strength Index }\end{array}$} & \multirow{3}{*}{ Tenotomy } & Small & 27 & 0.91 & \multirow{2}{*}{0.270} \\
\cline { 3 - 6 } & & Large & 28 & 1.01 & \\
\cline { 3 - 6 } & \multirow{3}{*}{ Tenodesis } & Total & 55 & 0.96 & \\
\cline { 3 - 6 } & & Small & 10 & 0.98 & \multirow{2}{*}{0.999} \\
\cline { 3 - 6 } & & Large & 12 & 0.98 & \\
\cline { 3 - 6 } & & Total & 22 & 0.98 & \\
\hline
\end{tabular}

Table 3 - Comparison between size of lesions and preoperative UCLA score.

\begin{tabular}{c|c|c|c}
\hline & Large lesions & Small lesions & $\mathbf{p}$ \\
\hline Tenotomy & 28 & 27 & \\
\hline Tenodesis & 12 & 10 & \multirow{2}{*}{$=0.659$} \\
\hline UCLA & 17.2 & 16.62 & \\
\hline
\end{tabular}

Table 4 - Age of patients (years) and outpatient follow-up (months).

\begin{tabular}{c|c|c|c}
\hline & Tenotomy & Tenodesis & $\mathbf{p}$ \\
\hline Mean age & 58.05 & 58.18 & $=0.635$ \\
\hline Mean postoperative follow-up & 41.84 & 45.36 & $=0.343$ \\
\hline Total of patients & 56 & 21 & 77 \\
\hline
\end{tabular}

Table 5 - Comparison between tenotomy and tenodesis for pain along the length of the bicipital groove, Popeye sign, and ESI.

\begin{tabular}{c|c|c|c}
\hline & Pain & Popeye sign & ESI \\
\hline Tenotomy & $3(5.5 \%)$ & $12(21.8 \%)$ & 0.96 \\
\hline Tenodesis & $3(13.6 \%)$ & $2(9.8 \%)$ & 0.98 \\
\hline$p$ & 0.345 & 0.327 & 0.955 \\
\hline
\end{tabular}


Table 6 - Comparison between the increases in UCLA score by group.

\begin{tabular}{c|c|c}
\hline & UCLA score increase & \\
\hline Mean & 14.53 & \\
\hline Tenotomy & 14.62 & \multirow{2}{*}{$\mathrm{p}=0.023$} \\
\hline Tenodesis & 15.95 & \\
\hline
\end{tabular}

There was a relationship between dominance and the side operated in the patient and an increased range of motion after surgery. We did not obtain statistically significant differences in the groups submitted only to tenotomy or to tenotomy with tenodesis for pain on palpation of the bicipital groove, Popeye sign, or ESI. Patients undergoing tenotomy with tenodesis had a more significant increase in the UCLA score from pre- to postoperation than patients who underwent only tenotomy.

\section{DISCUSSION}

Clinically, patients with lesions of the LHB may have pain of the intertubercular groove on palpation or during activities above the level of the head, presenting positive Yergason's, Speed, and O'Brian tests ${ }^{(16,17)}$. Such lesions, when untreated or undiagnosed, are common causes of shoulder pain and dysfunction following arthroscopic repair of the rotator cuff.

Eakin et $\mathrm{al}^{(18)}$ described three situations involving LHB lesions that, when present, make surgical intervention the most suitable therapeutic method. They are tendinopathy, subluxation of the medial tendon of the LHB, and degenerative and unstable SLAP lesions. Currently there is no consensus in the literature that defines which procedure is the most appropriate in the management of LHB lesions during rotator cuff repair ${ }^{(19)}$.

We evaluated the relationship between lesion size during arthroscopic rotator cuff repair and ESI. We demonstrated that the results were not statistically significant. We found no studies in the literature that performed similar analysis.

Failure rates for tenotomy with tenodesis procedure have been described ranging from 5 to $48 \%{ }^{(20,21)}$, and with the completion of only tenotomy, the range was from 13 to $35 \%^{(7,11)}$.

Both procedures produce a similar rate of good and excellent results, ranging from $40^{(22)}$ and $93 \%{ }^{(10)}$ in those undergoing tenotomy with tenodesis, while those undergoing tenotomy alone varied between $65^{(11)}$ and $90 \%{ }^{(7)}$.
In our study, the patients showed good clinical results, since they had an increased range of motion and UCLA score postoperatively.

The treatment may be based on age, sex and physical activities performed by the patient ${ }^{(22)}$. Some authors advocate only tenotomy ${ }^{(7,8,11)}$, a technically simple procedure that promotes rapid postoperative rehabilitation $^{(23,24)}$ and early return to activities ${ }^{(20,25)}$. However, it may lead to some implications for the biceps muscle and biomechanical changes in the elbow $^{(9)}$. Other authors advocate tenotomy with tenodesis $^{(9,10)}$ to prevent cosmetic deformities (Popeye sign) and to maintain the strength of elbow flexion and forearm supination ${ }^{(2)}$. We did not evaluate the time of patient rehabilitation and their return to daily activities.

Hawkins et $\mathrm{al}^{(26)}$ studied the strength of elbow flexion and forearm supination in three different groups. The first group was subjected only to tenotomy, the second was subjected to tenotomy with tenodesis, and the third was the control group (patients not undergoing tenotomy with or without tenodesis). No statistical difference was found between the groups in the strength parameters that were evaluated. This suggests that there is no noticeable loss of muscle strength after tenotomy with or without tenodesis. In our study, statistical analysis comparing the ESI values of the group of patients undergoing tenotomy without tenodesis and the patients in the tenotomy with tenodesis group also showed no statistically significant differences $(p=0.955)$. However, other studies have not shown the same results, with losses of forearm supination strength of up to $40 \%$ after tenotomy without tenodesis ${ }^{(5,23)}$. We did not assess the strength of supination for comparison.

Boileau et $\mathrm{al}^{(27)}$ compared groups of patients undergoing tenotomy without tenodesis with patients undergoing tenodesis alone in a sample of patients with irreparable rotator cuff injuries and found no statistical differences, assessing the Constant and Murley score $^{(28)}$ and pain in the intertubercular groove. Similar to Boileau et $\mathrm{al}^{(27)}$, in our study there was no statistical difference between the two groups in regards to pain on palpation of the intertubercular groove. However, patients in the tenotomy with tenodesis group showed an increased UCLA score that was statistically superior to the patients in the tenotomy without tenodesis group. Checchia et $\mathrm{al}^{(29)}$ 
reported good results in their cases according to the UCLA scale with tenotomy followed by tenodesis. In our results, a statistically significant difference was not found with respect to the Popeye sign. Almeida et $\mathrm{al}^{(30)}$ found this deformity in $35.1 \%$ of patients undergoing arthroscopic tenotomy alone.

\section{CONCLUSION}

In comparing patients undergoing tenotomy with or without LHB tenodesis associated with arthroscopic rotator cuff repair, the results were similar regarding Popeye sign, ESI, and pain on palpation in the intertubercular groove. However, changes in the UCLA scale scores pre- to postoperatively were greater for patients undergoing tenotomy with tenodesis.

Functional results were better in patients undergoing tenotomy with tenodesis of the LHB during arthroscopic repair of the rotator cuff. However, it is noteworthy that patients undergoing tenotomy without LHB tenodesis also showed good clinical results.

\section{REFERENCES}

1. Roukoz S, Naccache N, Sleilaty G. The role of the musculocutaneous and radial nerves in elbow flexion and forearm supination: a biomechanical study. J Hand Surg Eur. 2008;33(2):201-4.

2. Ahmad CS, EIAttrache NS. Arthroscopic biceps tenodesis. Orthop Clin North Am. 2003;34(4):499-506.

3. Sethi N, Wright R, Yamaguchi K. Disorders of the long head of the biceps tendon. J Shoulder Elbow Surg. 1999;8(6):644-54.

4. Barber FA, Field LD, Ryu RK. Biceps tendon and superior labrum injuries: decision making. Instr Course Lect. 2008;57:527-38.

5. Maynou C, Mehdi N, Cassagnaud X, Audebert S, Mestdagh H. [Clinical results of arthroscopic tenotomy of the long head of the biceps brachii in full thickness tears of the rotator cuff without repair: 40 cases]. Rev Chir Orthop Reparatrice Appar Mot. 2005;91(4):300-6.

6. Murthi AM, Vosburgh CL, Neviaser TJ. The incidence of pathologic changes of the long head of the biceps tendon. J Shoulder Elbow Surg. 2000;9(5):382-5.

7. Gill TJ, Mclrvin E, Mair SD, Hawkins RJ. Results of biceps tenotomy for treatment of pathology of the long head of the biceps brachii. J Shoulder Elbow Surg. 2001;10(3):247-9.

8. Walch G, Edwards TB, Boulahia A, Nové-Josserand L, Neyton L, Szabo I. Arthroscopic tenotomy of the long head of the biceps in the treatment of rotator cuff tears: clinical and radiographic results of 307 cases. J Shoulder Elbow Surg. 2005;14(3):238-46.

9. Berlemann U, Bayley I. Tenodesis of the long head of biceps brachii in the painful shoulder: improving results in the long term. J Shoulder Elbow Surg. 1995;4(6):429-35.

10. Checchia SL, Doneux PS, Miyazaki AN, Silva LA, Fregoneze M, Ossada A, et al. Biceps tenodesis associated with arthroscopic repair of rotator cuff tears. J Shoulder Elbow Surg. 2005;14(2):138-44.

11. Kelly AM, Drakos MC, Fealy S, Taylor SA, O'Brien SJ. Arthroscopic release of the long head of the biceps tendon: functional outcome and clinical results. Am J Sports Med. 2005;33(2):208-13.

12. Ahrens PM, Boileau P. The long head of biceps and associated tendinopathy. J Bone Joint Surg Br. 2007;89(8):1001-9.

13. Ellman $H$, Hanker $G$, Bayer M. Repair of the rotator cuff. End-result study of factors influencing reconstruction. J Bone Joint Surg Am. 1986;68(8):1136-44.

14. Koh KH, Ahn JH, Kim SM, Yoo JC. Treatment of biceps tendon lesions in the setting of rotator cuff tears: prospective cohort study of tenotomy versus tenodesis. Am J Sports Med. 2010;38(8):1584-90.

15. Ellman H, Garstman GM. Arthroscopic shoulder surgery and related procedures. Philadelphia: Lea \& Febiger; 1993.

16. Hitchcock $\mathrm{HH}$, Bechtol CO. Painful shoulder: observations on role of tendon of long head of the biceps brachii in its causation. J Bone Joint Surg.
1948;30(2):263-73. Disponível em: http://jbjs.org/data/Journals/JBJS/342/263. pdf. Acessado em: 2011 (Sep 27).

17. Yergason RM. Supination sign. J Bone Joint Surg. 1931;13(1):160. Disponível em: http://jbjs.org/data/Journals/JBJS/249/160.pdf. Acessado em: 2011 (Sep 27).

18. Eakin CL, Faber KJ, Hawkins RJ, Hovis WD. Biceps tendon disorders in athletes. J Am Acad Orthop Surg. 1999;7(5):300-10.

19. Frost A, Zafar MS, Maffulli N. Tenotomy versus tenodesis in the management of pathologic lesions of the tendon of the long head of the biceps brachii. Am J Sports Med. 2009;37(4):828-33.

20. Boileau P, Krishnan SG, Coste JS, Walch G. Arthroscopic biceps tenodesis: a new technique using bioabsorbable interface screw fixation. Arthroscopy. 2002;18(9):1002-12.

21. Becker DA, Cofield RH. Tenodesis of the long head of biceps brachii for chronic bicipital tendonitis. Long-term results. J Bone Joint Surg Am. 1989;71(3):376-81.

22. Lam F, Mok D. Treatment of the painful biceps tendon - Tenotomy or tenodesis? Current Orthopaedics. 2006;20:370-75. Disponível em: http://www.shoulderspecialist.org/pdf/treatment $\% 20$ of\%20the \%20painful\%20biceps $\% 20$ tendon.pdf. Acessado em: 2011 (Sep 27).

23. Mariani EM, Cofield RH, Askew LJ, Li GP, Chao EY. Rupture of the tendon of the long head of the biceps brachii. Surgical versus nonsurgical treatment. Clin Orthop Relat Res. 1988;(228):233-9.

24. Neviaser TJ, Neviaser RJ, Neviaser JS, Neviaser JS. The four-in-one arthroplasty for the painful arc syndrome. Clin Orthop Relat Res. 1982;(163):107-12.

25. Franceschi F, Longo UG, Ruzzini L, Rizzello G, Maffulli N, Denaro V. No advantages in repairing a type II superior labrum anterior and posterior (SLAP) lesion when associated with rotator cuff repair in patients over age 50: a randomized controlled trial. Am J Sports Med. 2008;36(2):247-53.

26. Hawkins RJ, Shank J, Kissenberth MJ, et al. A comparison of forearm supination and elbow flexion strength in patients with either long head of the biceps tenotomy or tenodesis. J Shoulder Elbow Surg. 2007;16(2):e64. Disponível em: http://www.jshoulderelbow.org/article/S1058-2746(07)00111-5/fulltext. Acessado em: 2011 (Sep 28).

27. Boileau P, Baqué F, Valerio L, Ahrens P, Chuinard C, Trojani C. Isolated arthroscopic biceps tenotomy or tenodesis improves symptoms in patients with massive irreparable rotator cuff tears. J Bone Joint Surg Am. 2007;89(4):747-57.

28. Constant $\mathrm{CR}$, Murley $\mathrm{AH}$. A clinical method of functional assessment of the shoulder. Clin Orthop Relat Res. 1987;(214):160-4.

29. Checchia SL, Santos PD, Miyazaki AN, Fregonezi M, Silva LA, Leite FSF, et al. Avaliação dos resultados da tenodese artroscópica do biceps, utilizando-se parafuso de interferência bioabsorvível. Rev Bras Ortop. 2007;42(8): 237-43.

30. Almeida A, Roveda G, Valin MR, Almeida MC, Agostini AP, Sheifler C. Avaliação da deformidade estética após a tenotomia da cabeça longa do biceps na artroscopia do ombro. Rev Bras Ortop. 2008;43(7):271-8. 